\title{
Procedimentos para o uso inovador do SEER nos processos de avaliação de projetos de pesquisa: estudo de caso na UERGS
}

\begin{tabular}{ll}
\hline Erli Schneider Costa & $\begin{array}{l}\text { Pró-Reitoria de Pesquisa e Pós-Graduação (Pro- } \\
\text { PPG). Universidade Estadual do Rio Grande do } \\
\text { Sul (UERGS). }\end{array}$ \\
$\begin{array}{ll}\text { Gabriela Oliveira de } \\
\text { Castro }\end{array}$ & $\begin{array}{l}\text { Superintendência de Planejamento (Suplan). UE- } \\
\text { RGS. }\end{array}$ \\
\hline Rafael Kreutz & $\begin{array}{l}\text { Mestrando em Gestão de Organizações Públicas. } \\
\text { Universidade Federal de Santa Maria (UFSM). } \\
\text { E-mail: rafael.kreutz@gmail.com }\end{array}$ \\
\hline $\begin{array}{l}\text { Israel Cefrin } \\
\text { Laura Clara Gehrke }\end{array}$ & $\begin{array}{l}\text { Doutorando em Design \& Tecnologia. Universi- } \\
\text { dade Federal do Rio Grande do Sul (UFRG). }\end{array}$ \\
$\begin{array}{l}\text { Fundação de Economia e Estatística (FEE) } \\
\text { E-mail: israel.cefrin@gmail.com }\end{array}$ \\
$\begin{array}{l}\text { Clódis de Oliveira An- } \\
\text { drades Filho }\end{array}$ & $\begin{array}{r}\text { ProPPG-UERGS. } \\
\text { E-mail: laura-gehrke@uergs.edu.br }\end{array}$ \\
\hline
\end{tabular}

Recebido em: 10 set. 2017. Revisado em: 11 set. 2017 Aceito: 27 set. 2017. DOl: http://dx.doi.org/10.21674/2448-0479.33.562-587 


\section{Resumo}

O gerenciamento de projetos é uma atividade que envolve diversas ações que vão desde o recebimento dos mesmos pelos órgãos responsáveis, avaliação, classificação e outras ações necessárias para que 0 andamento desses possa ser acompanhado, até a divulgação do resultado final. Neste sentido a Pró-Reitoria de Pesquisa e PósGraduação da Universidade Estadual do Rio Grande do Sul (UERGS) apresenta neste artigo o uso inovador do Sistema Eletrônico de Editoração de Revistas (SEER) utilizado para o recebimento e gerenciamento dos projetos de pesquisa que são submetidos para atender editais internos da Instituição. São apresentados diagramas de fluxo de procedimentos para o processo de submissão e avaliação de projetos de pesquisa submetidos aos editais da UERGS. Os autores entendem que desde o início do uso do SEER para os processos de gestão dos projetos de pesquisa na instituição o fluxo ficou mais dinâmico e ágil e permite o registro de todas as etapas que envolve $m$ o processo substituindo com melhor capacidade de organização e distribuição das ações em relação ao uso do e-mail e de outras formas de gestão de projetos usados anteriormente pela Pró-Reitoria.

Palavras-chave: Gerenciamento de projetos. Sistema Eletrônico de Editoração de Revistas. Gestão de projetos. Inovação. 


\section{Abstract \\ Procedures for the innovative use of SEER in the evaluation processes of research projects: a case study at UERGS}

Project management is an activity that involves several actions as receipt of the same by the responsible team, evaluation, classification and other actions necessary in the way that the progress of the projects can be monitored. In this sense, the Pro-Rectory of Research and Postgraduate Studies of the State University of Rio Grande do Sul (UERGS) presents in this paper an innovative use of the Open Journal System (OJS) used to receive and manage research projects that are submitted to attend the institution's internal selection processes. The paper presentes the process flow using diagrams to ilustrate the submission and evaluation processes of research projects submitted to the UERGS. The authors understand that the use of OJS in the management research projects by the institution made possible to become more dynamic and agile. The OJS use enabled the registration of all stages that involve the processes relating to management of projects replacing with great superiority the use of e-mail and other forms previously used by the University.

Keywords: Project management. Open Journal System. University. Administration. 


\section{Introdução}

O Sistema Eletrônico de Editoração de Revistas (SEER) é uma customização do Open Journal System (OJS), software live de gestão e publicação de revistas eletrônicas desenvolvido pelo Public Knowedge Project (PKP) da University of British Columbia no Canadá (INSTITUTO BRASILEIRO DE INFORMAÇÃO EM CIÊNCIA E TECNOLOGIA, 2017). O SEER é usado no Brasil desde junho de 2004 quando a revista Ciência da Informação do Instituto Brasileiro de Informação em Ciência e Tecnologia (IBICT) passou a ser publicada na versão 1.15 do SEER/OJS (ARELLANO et al., 2005). Segundo Arellano et al. (2005) é uma ferramenta que permite completa autonomia na tomada de decisões sobre o fluxo editorial: a publicação e o acesso por parte do editor que define as etapas do processo editorial de acordo com a política definida pela revista, dispondo de assistência e registro on-line em todas as fases do sistema de gerenciamento.

Em dezembro de 2016 o SEER/OJS atingiu mais de $\mathbf{1 0 . 0 0 0}$ periódicos ativos hospedados, tornando-se "a principal plataforma de publicação on-line, com mais títulos ativos do que qualquer outro fornecedor, incluindo as principais editoras comerciais" (PUBLIC KNOWLEDGE PROJECT, 2015). América Latina e Caribe tem o maior número de revistas científicas eletrônicas hospedadas no SEER/OJS, totalizando 3.295 periódicos (Tabela 1), sendo que o Brasil é o país com maior representatividade na região, e no mundo, com 1.934 revistas. No universo de periódicos ativos (considerados ativos aqueles periódicos que publicaram pelo menos 10 artigos no ano em que foram avaliados) existem mais de 420.000 artigos publicados, disponíveis sem custos (PUBLIC KNOWLEDGE PROJECT, 2016). 
Tabela 1: Total de periódicos por região usando o Sistema Eletrônico de Editoração de Revistas (Open Journal System) em 2016.

\begin{tabular}{cc}
\hline Região & $\begin{array}{c}\text { Número de Revistas } \\
\text { no OJS }\end{array}$ \\
\hline América Latina e Caribe & 3.321 \\
\hline Europa e Ásia Central & 2.677 \\
Leste da Asia e Pacífico & 2.353 \\
América do Norte & 1.371 \\
Sul da Ásia & 300 \\
Oriente Médio e Norte da África & 173 \\
\hline Árica subsaariana & 362 \\
\hline Total & $\mathbf{1 0 . 5 5 1}$ \\
\hline
\end{tabular}

Fonte: https://pkp.sfu.ca/ojs/ojs-usage/ojs-\%20map/

Ao longo dos anos, verificou-se também que o SEER/OJS está sendo usado como forma alternativa para repositório, por exemplo, de relatórios internos, Sistema de Gestão de Aprendizagem, para apresentações de teses e de outras formas ainda (PUBLIC KNOWLEDGE PROJECT, 2016). Nos números apresentados anteriormente nenhum destes usos inovadores estão incluídos o que significa que o SEER/OJS tem uma utilidade pública ainda superior. Para documentar o uso inovador do SEER/OJS a PKP incluiu em sua principal conferência "PKP Scholarly Publishing Conference" que está na sua $6^{\mathrm{a}}$ edição, um tópico específico para tais relatos: "Innovative uses of PKP software applications" (PUBLIC KNOWLEDGE PROJECT, 2017), momento no qual foi apresentado resumo sobre o uso do SEER pela Uergs (SILVA et al., 2017).

Vale ressaltar que, desde a revolução industrial e do advento do pensamento científico, o gerenciamento de estratégias, processos e modelos são cada vez mais necessários de forma a garantir a entrega de produtos e serviços com geração de valor e para assegurar a sustentabilidade das diversas organizações (empresas, instituições de ensino e de pesquisa, entre outros) (LARUCCIA et al., 2012). Neste contexto as organizações atuam em duas vertentes: Gerenciamento 
dos Processos - relativa à gestão da rotina e das decisões do diaa-dia, e o Gerenciamento de Projetos - responsável pelas decisões de médio e longo prazo das organizações (CAMPOS, 2004). Considerando a necessidade de gerenciamento de projetos - não somente projetos de gestão, mas projetos de pesquisa e inovação - e que estes processos de gestão agregam valor a médio e longo prazo para a universidade no que se refere à geração de conhecimentos entendemos ser indispensável apresentar novas ideias para o gerenciamento e acompanhamento dos projetos (LARUCCIA et al., 2012).

Entretanto a gestão de projetos no que diz respeito a seus trâmites nas universidades ainda faz uso de modos pouco práticos, como o uso de e-mails. Como referência podemos citar o caso da nossa instituição, UERGS, que inicialmente fazia uso de documentos impressos e CDs e em seguida passou a usar processo eletrônico por e-mail, que ocasionava falhas e retrabalho constante, com intenso movimento de troca de e-mails e processos repetitivos e falhos no momento de submissão das propostas para avaliadores externos.

Sendo assim, neste artigo apresentamos o uso inovador do SEER/OJS como ferramenta adequada para o gerenciamento de projetos, conforme experiência da Pró-Reitoria de Pesquisa e Pós-Graduação. Constatando que os processos de submissão e avaliação de projetos passam por um processo similar ao de submissão de artigos científicos publicados em revistas o OJS/SEER se mostrou um sistema eficiente de gerenciamento. O uso de sistemas e recursos que possam facilitar e acelerar este processo são indispensáveis sendo que o SEER pode ser considerado uma excelente opção devido a inúmeras vantagens, entre as quais, destacamos o custo zero e a fácil adaptação para a proposta de avaliação de projetos. O objetivo deste artigo é apresentar por meio de diagramas de fluxo de procedimentos a experiência do uso do Sistema Eletrônico de Editoração de Revistas (SEER) para o processo de submissão e avaliação de projetos de pesquisa submetidos aos editais da Universidade Estadual do Rio Grande do Sul (UERGS). 


\section{Materiais e Métodos}

As informações apresentadas na sequência se referem aos procedimentos adotados pela UERGS, Pró-Reitoria e Pós-Graduação, podendo ser categorizado como relato de experiência ou estudo de caso após 3 anos da adoção do sistema. Conforme Calazans (2007) é uma estratégia de pesquisa que pede avaliação qualitativa, pois seu objeto é o estudo de uma unidade social que se analisa profundamente. "A pesquisa qualitativa dirige-se à análise de casos concretos em suas peculiaridades locais e temporais [...]" (FLICK, 2009, p. 37). Neste sentido, adotamos o estudo de caso por se tratar de uma perspectiva empírica e voltada para problemas concretos e locais.

Para os processos de submissão e de avaliação por pares dos projetos submetidos à Pró-Reitoria de Pesquisa e Pós-Graduação (ProPPG) da UERGS passou a utilizar em 2015 o Sistema Eletrônico de Editoração de Revistas (SEER) disponível no link http://revista.uergs.edu.br/. Este é o mesmo endereço anteriormente utilizado pela instituição para os procedimentos editoriais da Revista Eletrônica Científica da UERGS. Os procedimentos adotados pela ProPPG como forma de aprimorar e acelerar os trâmites do processo de submissão de projetos pelos docentes da instituição para editais específicos (e/ou para registro dos projetos em andamento) estão representados neste artigo por meio de diagramas. Para criar os mesmos foram utilizadas as ferramentas de SmartArt e Gráficos do Microsoft Word.

Ressaltamos que informações adicionais, quando necessárias para ilustrar o artigo, foram incluídas durante a redação, de acordo com as experiências vivenciadas pela equipe da ProPPG. Desta forma esperamos colaborar com a orientação dos futuros utilizadores do SEER para a submissão de projetos de pesquisa (ou outros) e também os potenciais coordenadores de projetos de forma a reduzir a ocorrência de erros durante o uso do sistema. A seguir, aborda-se o relato da experiência do caso estudado. 


\section{Resultados e Discussão}

Historicamente, a ProPPG recebia os projetos de pesquisa por meio de documentos impressos e arquivos salvos em CDs, com as mudanças na Coordenação de Pesquisa o recebimento dos projetos foi alterado e passamos a recebê-los exclusivamente por via eletrônica. O processo de envio para os revisores externos era realizado por e-mail, ocasionando retrabalho e falhas constantes, além da demora na resposta por parte dos revisores. Os principais problemas registrados neste processo de submissão iam desde a etapa de submissão propriamente dito, no processo de recebimento dos projetos pela ProPPG, até dificuldades durante o envio dos projetos para os revisores e no recebimento dos pareceres, bem como no arquivamento do processo; e resgate de informações quando necessárias. Era comum que, por questões técnicas (por exemplo, reduzido espaço no e-mail institucional ou excesso no tamanho dos arquivos submetidos) projetos não fossem recebidos no prazo adequado, sendo necessário recebê-los fora do período do Edital, o que desestruturava $o$ andamento do processo como um todo. No intuito de tentar sanar este problema um e-mail do provedor Gmail foi criado e utilizado como repositório. Mesmo assim, no início do processo, devido à configuração inicial do Gmail os e-mails com assuntos idênticos ficavam agrupados em conversas e não eram acessados, faltando o registro de alguns projetos. Em situações extremas, a ProPPG recebia reclamações de coordenadores a respeito de projetos não listados nem avaliados após a conclusão de todo o processo, o que gerava conflitos e prejuízos pela exclusão por não recebimento de projetos dos Editais.

Em relação ao envio dos projetos para os revisores externos verifica-se pelo registro de e-mails institucionais e por meio de relatos de experiências dos autores deste artigo que os principais problemas eram: 1) envio de e-mail sem os anexos, 2) envio de assunto do email sem alteração do título do projeto, 3) envio equivocado de projetos com temas diversos das áreas de estudo dos revisores cadastrados, 4) não recebimento da confirmação dos avaliadores do aceite da revisão, 5) não recebimento dos formulários preenchidos, 6) demora 
no envio dos atestados para os revisores, 7) reduzida base de revisores cadastrada e dificuldade de seleção de revisores acumulando muitos projetos para poucos revisores; entre outras.

A partir de 2015 (Edital 011/2015) a ProPPG passou a adotar de forma inovadora o uso do SEER para os processos de submissão de projetos pelos docentes da Instituição e para o processo de avaliação externo. Para facilitar a adequação do uso do SEER pelos docentes foi inicialmente criada uma apresentação em Power Point com as orientações para submissão de projetos. Foram encontradas algumas dificuldades em um primeiro momento no uso do novo sistema, mas as mesmas foram rapidamente superadas e no segundo processo de submissão (Edital 013/2016) os docentes já estavam adaptados à nova forma adotada pela ProPPG. Na sequência a Pró-Reitoria de Extensão adotou o uso do SEER para recebimento dos projetos de Extensão da UERGS, relatando uma experiência extremamente positiva com aceleração dos fluxos decorrentes do processo de avaliação.

Sendo assim, com base nos relatos acima e com o intuito de auxiliar a adoção de processos mais eficientes por outros setores da UERGS e também por outras instituições apresentamos abaixo os fluxos e processos adotados pela ProPPG conforme objetivo do artigo.

\section{Fluxo geral macro}

O processo de submissão de projetos aos Editais da ProPPGUERGS seguem um fluxo macro geral, que resume o processo de submissão e de avaliação (Figura 1).

Algumas etapas ocorrem concomitantemente, por exemplo, a partir da submissão do primeiro projeto já é possível dar início ao processo de revisão dos projetos iniciando-se o processo de encaminhamento para os revisores. Assim o processo se torna mais dinâmico e ao chegar ao final do período de submissões grande parte dos projetos já foi encaminhado aos revisores e alguns já estão revisados 
fazendo com que o processo tenha maior chance de ser finalizado no prazo previsto ou com antecedência. Assim o trabalho não fica acumulado em apenas um momento, sendo dividido pelo grupo no decorrer do período previsto pelo Edital.

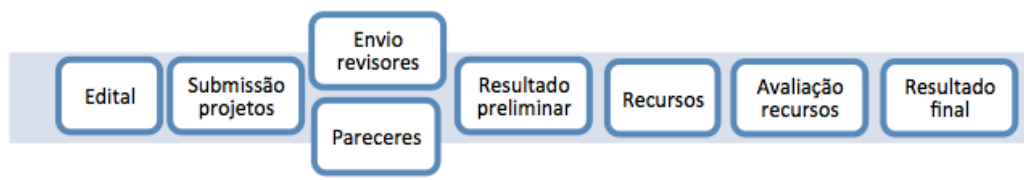

Figura 1 - Fluxo geral do processo de submissão e avaliação dos projetos submetidos à Pró-Reitoria de Pesquisa e Pós-Graduação da Universidade Estadual do Rio Grande do Sul (ProPPG-UERGS).

\section{Configuração do SEER para recebimento dos projetos}

Em conjunto com os procedimentos para a publicação do Edital é realizada a configuração do SEER para recebimento dos projetos. A configuração é feita para cada Edital com a criação de uma nova "Revista" no sistema, pelo Administrador do Portal. Os passos para criação da (revista = edital projeto) seguem a sequência:

Acessar o sistema como Administrador do Portal (login e senha) Página do usuário - Administrador do Portal - Revistas hospedadas - Criar Revista.

Neste momento incluímos o título da revista (geralmente o Edital) e inserimos um caminho (IC + ano, por exemplo). Após os passos anteriores ao retornarmos para a "Página do Usuário" a revista criada estará disponível em "Minhas revistas". Desta forma é possível 
individualizar os processos por Edital e manter por tempo indeterminado o arquivo de todas as submissões, avaliações e comunicações com revisores e autores (repositório).

\section{Funções do Editor Gerente}

Após criar a Revista (função do Administrador do Portal) o Editor Gerente é responsável por Configurar todo o sistema. Para tal em "Página do Usuário" basta clicar sobre o nome da Revista para ser direcionado para a Administração (Figura 2), momento no qual será possível configurar os passos de submissão, importar os "autores" de outras revistas (aqui usando como fator de seleção a palavra "uergs" nos e-mails), e dar funções (papéis) a todos que irão auxiliar no processo de avaliação dos projetos.

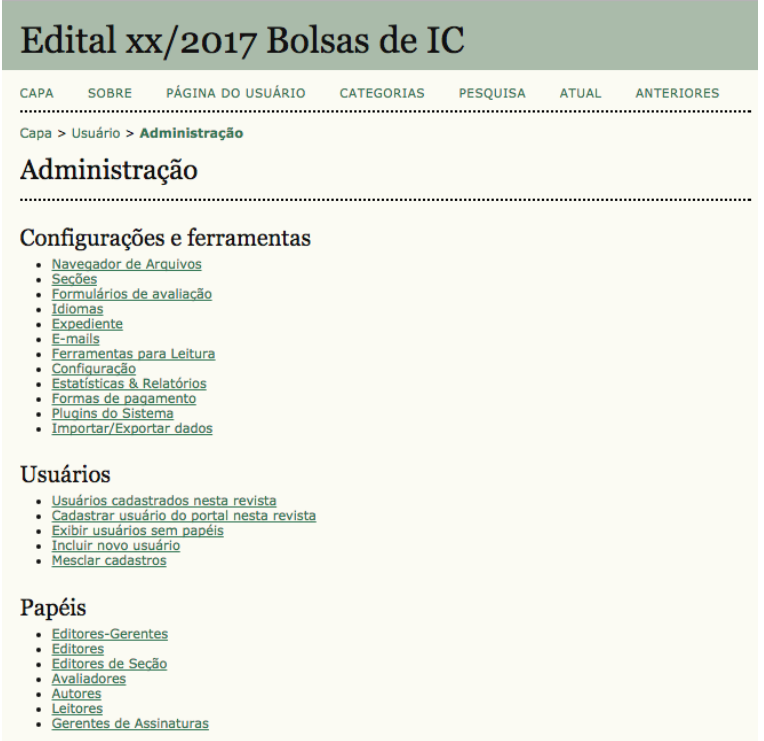

Figura 2 - Tela "Administração" na qual o Editor Gerente tem acesso a todo o processo de configuração da Revista que irá receber os projetos submetidos ao Edital. 
Incluímos abaixo os itens (e as sugestões de configuração) necessárias para que o processo possa ser iniciado. Existem itens que são dispensáveis pois são específicos para revistas científicas por isso destacamos somente os itens imprescindíveis para garantir o andamento do processo de submissão de projetos para os Editais.

- Sessões. Definir o tipo de "projeto" que será recebido. Clicar em Incluir Sessão. Na página que abre modificar Título da seção (Projetos de Iniciação Científica) e Abreviatura (PIC). Não é necessário assinalar nenhum dos outros itens disponíveis. Salvar irá voltar para a página anterior. Excluir o item Artigos. Retornar para Administração.

- Formulários de avaliação. Criar novo formulário. Incluir o Título do formulário (Projetos IC Edital xxx/2017). Salvar. Na próxima página clicar em Editar. Logo abaixo da palavra Detalhes (e ao lado da mesma palavra) clicar na opção "Campos" e em seguida "Criar novo campo". Em cada novo campo é necessário informar a Pergunta (item a ser avaliado), se o Campo é obrigatório e se a resposta será disponibilizada para o autor (Incluído na mensagem ao autor) no momento de envio dos pareceres/resultado. O "Tipo de campo" (texto curto, assinalar opções...) também é obrigatório. A ProPPG considera importante informar aos autores sobre os pareceres pois as contribuições dos revisores externos poderão ser utilizadas para futuras submissões interna e externamente visando a captação de fomento de outros órgãos das diversas esferas (municipais, estaduais, federais, internacionais). Após criar o formulário com todas as questões a serem avaliadas é necessário "Ativar" o mesmo para que, no momento de envio para os avaliadores, ele esteja disponível.

- E-mails. Este item apresenta e-mails padrões que são enviados aos revisores e outros para serem enviados aos autores com as 
decisões. Sugere-se editar somente aqueles que serão utilizados no processo de revisão dos projetos sendo os principais: SUBMISSION ACK (Editor de seção para autor / Agradecimento pela submissão); REVIEW REQUEST ONECLICK (Editor de Seção para Avaliador); REVIEW ACK (Editor de Seção ao Avaliador Agradecimento pela avaliação); as decisões editorias (EDITOR DECISION ACCEPT; DECLINE). O texto vem pré-produzido com linguagem de submissão/aceite/resposta de artigo científico. Sugere-se apenas modificar as palavras chaves de artigo para projeto e outras adequando a linguagem. Importante não modificar os links automáticos pré-incluídos para evitar erros no momento em que o e-mail é gerado automaticamente. É possível ainda criar e-mails que não estejam na lista e que sejam necessários.

- Configuração. É necessário incluir os dados obrigatórios em todas as páginas. O responsável pelos Editais deverá avaliar item a item se existe algum não obrigatório que possa ser útil no momento da submissão.

- 1) Detalhes: itens 1.1, 1.2 e 1.3. Sugere-se repetir o Contato Principal e o Suporte Técnico.

- 2) Políticas: Assinalar: Processo de avaliação padrão. Opções para avaliação. O item "Tempo de Avaliação" pode ser alterado. Sugere-se inicialmente manter duas semanas. Sugere-se ainda assinalar os itens "Lembretes aos avaliadores"; "Habilitar acesso 1-clique" e "Avaliadores terão acesso ao documento somente após indicar disponibilidade". Assinalar o item 2.4.

- 3) Submissões: Manter no Item "Condições para a submissão" todos os itens do Edital indispensáveis de forma que o coordenador possa verificar neste momento se está cumprindo com o Edital. Sugere-se alterar os itens 
que são específicos para artigos modificando a linguagem para projetos. O Item 3.6 permite notificar ao autor (coordenador) a conclusão de submissão. Assinalar $01^{\circ}$ item. Todos os demais itens são dispensáveis.

- 4) Administração: No item "Cadastro de usuários" assinalar Avaliadores como forma de cadastro uma vez que os Autores são cadastrados pela ProPPG. Não há necessidade de nenhuma outra alteração.

- 5) Visual: Item 5.8. Permite aumentar o número de itens por página o que pode ser útil quando pretende-se fazer buscas em todos os projetos ou em todas as opções de avaliadores (usando CTRL $+F$ ). Sugere-se manter pelo menos 1000 itens por página. Não há necessidade de outras alterações.

\section{- Usuários}

- Cadastrar usuário do portal nesta revista: Neste item é possível selecionar por e-mail e definir papéis específicos. Para o caso da ProPPG-UERGS importamos com o papel de autor todos os cadastros em que o e-mail contêm a sigla "uergs". Cadastrar usuário do portal - E-mail - contém - uergs - Cadastrar como Autor. Rodar até o final da página e clicar em "Selecionar todos" e na sequência clicar em "Cadastrar Usuários Selecionados". Todos os cadastros com e-mails contendo "uergs" serão automaticamente cadastrados como autores. Docentes que não tenham usado o e-mail institucional ou que tenham alterado o e-mail no cadastro deverão solicitar inclusão diretamente para a ProPPG. Usamos este mesmo passo-a-passo para cadastrar os avaliadores. É indispen- 
sável que os professores da instituição não fiquem cadastrados como avaliadores pois o processo de avaliação do Edital exige que os avaliadores sejam externos.

- Papéis: Neste item é possível encontrar cadastros específicos para atribuir diversas funções como de avaliadores, autores ou editores de acordo com a necessidade dos processos previstos no Edital.

Utilizando estas configurações é possível dar início ao recebimento das propostas submetidas ao Edital. Ressaltamos que é possível fazer adequações durante o processo de submissão e de avaliação como, por exemplo, ajustes no prazo para respostas dos revisores que pode ser maior no início do processo e ir sendo reduzido, à medida que os prazos vão se esgotando. Assim percebemos que o SEER é flexível e dinâmico podendo ser adaptado às necessidades temporais do processo de avaliação dos projetos.

\section{Processo de submissão (coordenadores)}

\section{Cadastro autores (coordenadores)}

O cadastro de todos os docentes da instituição é realizado pela ProPPG utilizando o e-mail institucional conforme detalhado anteriormente. Os docentes novos na instituição solicitam cadastro para a ProPPG e após o $1^{\circ}$ cadastro irão usar o mesmo login para todos os Editais. Em caso de necessidade de receber login e/ou senha basta solicitar no item "Esqueceu a senha", incluindo o e-mail.

\section{Início do processo de submissão}

Para iniciar o processo de submissão o coordenador do projeto acessa o sistema e escolhe o Edital correto ("Revista") que, no caso da ProPPG-UERGS tem o nome do Edital publicado (Edital 
011/2015; Edital 013/2016; Edital xx/2017). Após isso realizar o Login, acessar a Página do usuário, clicar no item "Autor" e "Iniciar nova Submissão".

Após "Iniciar nova submissão" o sistema apresenta o Passo 1 do processo de submissão (Figura 3). É possível verificar o título correto do Edital antes de iniciar o processo (no alto logo abaixo do endereço da página). É imprescindível realizar a submissão do projeto na área correta, pois de outra forma o projeto será desclassificado.

Os itens "Seção" e "Condições para submissão" são utilizados pela ProPPG-UERGS para que o coordenador informe a Área temática do projeto (dentro das áreas previstas pelo Documento de Fórum de Áreas da UERGS (2014) e o Check List que deve ser cumprido pelo coordenador para atender ao Edital (Figura 3).

\section{Passo 1. Iniciar submissão}

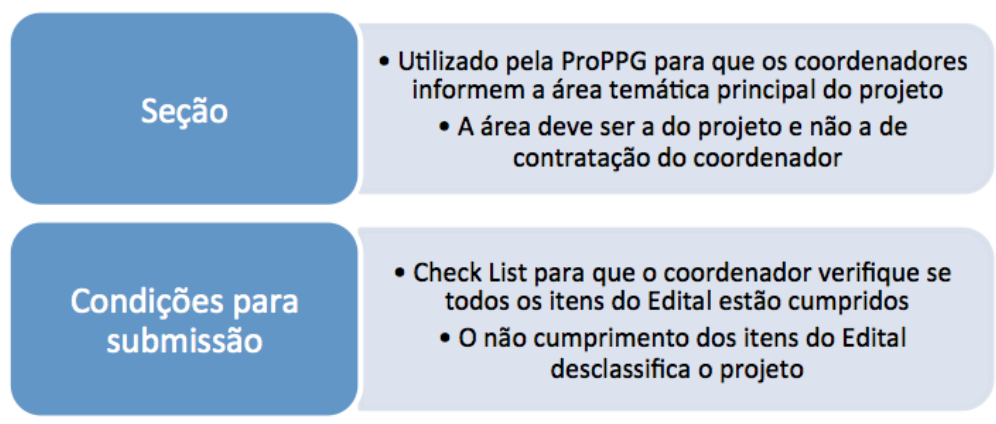

\section{Salvar e Continuar para o Passo 2}

Figura 3 - Passo 1 da submissão de projetos adotado pela Pró-Reitoria de Pesquisa e Pós-Graduação da Universidade Estadual do Rio Grande do Sul (ProPPG-UERGS). 
Em seguida o coordenador é ser direcionado para o Passo 2, momento no qual o projeto principal deve ser inserido (Figura 4). Os demais itens solicitados pelo edital deverão ser inseridos no Passo 4.

\section{Passo 2. Transferência do Manuscrito}

Neste item o PROJETO PRINCIPAL deve ser anexado. Atenção!!! Os autores não devem estar identificados em nenhum item da proposta.

\section{Transferir arquivo Escolher Arquivo Transferir}

\section{Salvar e Continuar para o Passo 3}

Figura 4 - Passo 2 do processo de submissão de projetos adotado pela Pró-Reitoria de Pesquisa e Pós-Graduação da Universidade Estadual do Rio Grande do Sul (ProPPG-UERGS).

Após a transferência do projeto de pesquisa a etapa seguinte é informar os dados do coordenador ( $1^{\circ}$ autor) e colaboradores; além do título do resumo do projeto (Figura 5). Estes itens são obrigatórios . Os demais itens são opcionais mas sugere-se que sejam inseridas as palavras-chaves, diferentes do título, para auxiliar no momento da busca por revisores. 


\section{Passo 3. Metadados da submissão}

Os dados de todos os colaboradores devem ser informados por meio da opção "Incluir autor". Clicar nesta opção o número de vezes suficiente para inserir todos os colaboradores.

\section{Salvar e Continuar para o Passo 4}

Figura 5 - Passo 3 da submissão de projetos adotado pela Pró-Reitoria de Pesquisa e Pós-Graduação da Universidade Estadual do Rio Grande do Sul (ProPPG-UERGS).

Conforme mencionado anteriormente a transferência dos documentos suplementares exigidos pelo Edital deverá ser feita no Passo 4 (Figura 6). Neste momento o coordenador deve ter atenção para que os autores não sejam identificados nos documentos para evitar a desclassificação do projeto.

\section{Passo 4. Transferência de documentos suplementares}

Inserir um a um os documentos suplementares (Plano de bolsa, Atividades colaboradores, Pontuação CV coordenador e outros conforme Edital).

Não identificar nenhum documento pois o revisor irá desclassificar projetos em que seja possível identificar coordenador e colaboradores

\section{Salvar e Continuar}

Figura 6 - Passo 4 da submissão de projetos adotado pela Pró-Reitoria de Pesquisa e Pós-Graduação da Universidade Estadual do Rio Grande do Sul (ProPPG-UERGS). 
O Passo 5 é o momento de conclusão da submissão da proposta sendo imprescindível que seja realizado até o final pelo coordenador (Figura 7). Caso este passo não seja finalizado o projeto não será submetido. A data de submissão que fica registrada no sistema é a do momento em que o botão "Concluir submissão" é ativado (não a do momento de criação da submissão). Caso o coordenador clique neste botão somente após o final do prazo o projeto será desclassificado por ter sido submetido após o prazo previsto no Edital.

\section{Passo 5. Confirmação da submissão}

Neste passo o coordenador verifica se todos os documentos foram incluídos. Se necessário pode retornar às etapas anteriores.

Para finalizar é obrigatório clicar no botão representado abaixo

\section{Concluir Submissão}

Observação: Submissões nas quais os coordenadores não clicarem na opção "Concluir submissão" não são recebidas.

Na página seguinte o coordenador pode verificar se tem submissão ativa. Autor - 1 Ativo (ou o número de projetos submetidos)

Figura 7 - Passo 5 da submissão de projetos adotada pela Pró-reitoria de Pesquisa e Pós-Graduação da Universidade Estadual do Rio Grande do Sul (ProPPG-UERGS).

\section{Processo de recebimento dos projetos pela ProPPG}

O SEER é configurado para que os Editores responsáveis (no caso Coordenação de Pesquisa) recebam e-mail informativo sobre a submissão tão logo o projeto seja enviado pelo coordenador. Após o recebimento dos projetos os responsáveis pelo processo encami- 
nham para os Revisores que irão avaliar se o projeto submetido cumpre ou não as diretrizes do Edital, e também farão uma avaliação da forma, do conteúdo, da coerência e atualização da referências (conforme itens constantes no Edital). Como ouve um aumento no número de projetos submetidos ano a ano a ProPPG-UERGS não analisa os projetos quanto ao atendimento do Edital antecipadamente, ficando a cargo do Coordenador verificar e zelar pelo cumprimento do Edital assim como ocorre nos Editais externos. Entre os itens do Edital que preveem a desclassificação dos projetos está a falta de envio de documentação ou a identificação dos autores na proposta. Esta análise é a primeira a ser realizada pelos revisores de acordo com o Formulário de Avaliação.

\section{Revisores e envio dos projetos para avaliação}

O cadastro de revisores é concomitante com todas as etapas do processo e pode ser contínuo para que a base de dados permaneça atualizada. É imprescindível que os revisores ao se cadastrarem preencham adequadamente o item "Área de Interesse para avaliação" ou não é possível localizar o avaliador pela busca por palavra-chave no sistema. O perfil pode ser adequado pelo próprio revisor a qualquer tempo, devendo ser mantido atualizado. Os revisores são importados de uma "Revista" para outra e devem ser externos à instituição, desta forma orientamos que, caso algum docente receba projetos para avaliar, decline do convite clicando na opção "Indisponível para avaliação". A avaliação é feita por pelo menos dois revisores e obedece o sistema duplo-cego, salvo quando o revisor solicita algum tipo de contato com os autores com o objetivo de estreitar uma parceria. 


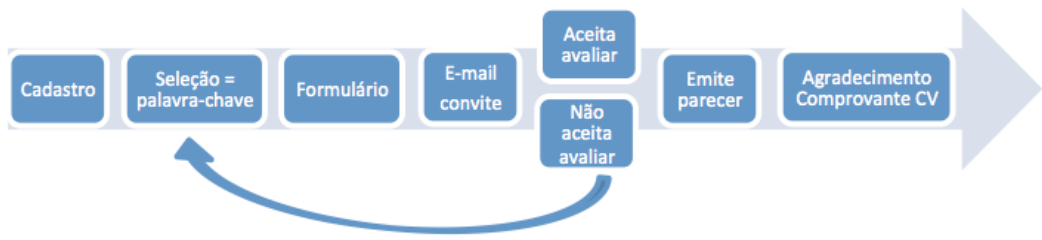

Figura 8 - Passos do processo de seleção de revisores, recebimento das avaliações e emissão de comprovante curricular de acordo com a Pró-Reitoria de Pesquisa e Pós-Graduação da Universidade Estadual do Rio Grande do Sul (UERGS).

A seleção do avaliador é feita por palavras-chaves no sistema e os projetos são enviados inicialmente para três avaliadores (Figura 8). O Editor responsável deve selecionar o formulário adequado e disparar o envio de um e-mail automático (configurado durante a etapa de configuração do SEER). O revisor recebe as informações sobre o projeto e informa no sistema se aceita ou não avaliar dentro do prazo o projeto em questão. Após enviarem os pareceres os revisores recebem pelo sistema um e-mail de confirmação de conclusão da avaliação e na sequência uma declaração para comprovação curricular. Todo o processo é on-line sendo que o envio de comprovação em meio físico só é realizado quando o avaliador solicita especificamente o envio da mesma.

\section{Compilação dos resultados}

Outra vantagem do uso do SEER é a emissão de estatísticas e relatórios com as avaliações dos projetos que permitem gerar os resultados de forma dinâmica e eficiente. Para acessar estas possibilidades o Editor-gerente acessa o item "Administração" e na sequên- 
cia "Estatísticas e Relatórios" em Configurações e Ferramentas (Figura 9a). A página que abre (Figura 9b) mostra as diversas estatísticas entre elas o total de submissões, o tempo de avaliação, percentual de projetos aceitos e rejeitados.

Além disso permite a emissão de relatórios sendo que, para projetos, os mais utilizados são "Relatório de avaliação" e "Relatório de artigos" (Figura 9b, final da página). O Relatório de artigos permite gerar a lista de projetos, com ID e coordenadores para publicar a lista de projetos submetidos ao edital. Já o Relatório de avaliação permite uma visualização geral da avaliação de cada um dos projetos submetidos e auxilia para gerar a lista final de projetos aprovados e não aprovados. Vale lembrar que as avaliações são enviadas diretamente ao coordenador tão logo o processo seja finalizado possibilitando que o mesmo tenha acesso aos itens e as considerações realizadas pelos avaliadores. A ideia é que, mesmo os projetos aprovados, recebam os pareceres para que os coordenadores possam avaliar as considerações e, se acharem adequadas, incluírem nos seus projetos de forma a aprimorar os mesmos ou melhorar avaliação em próximas submissões. 

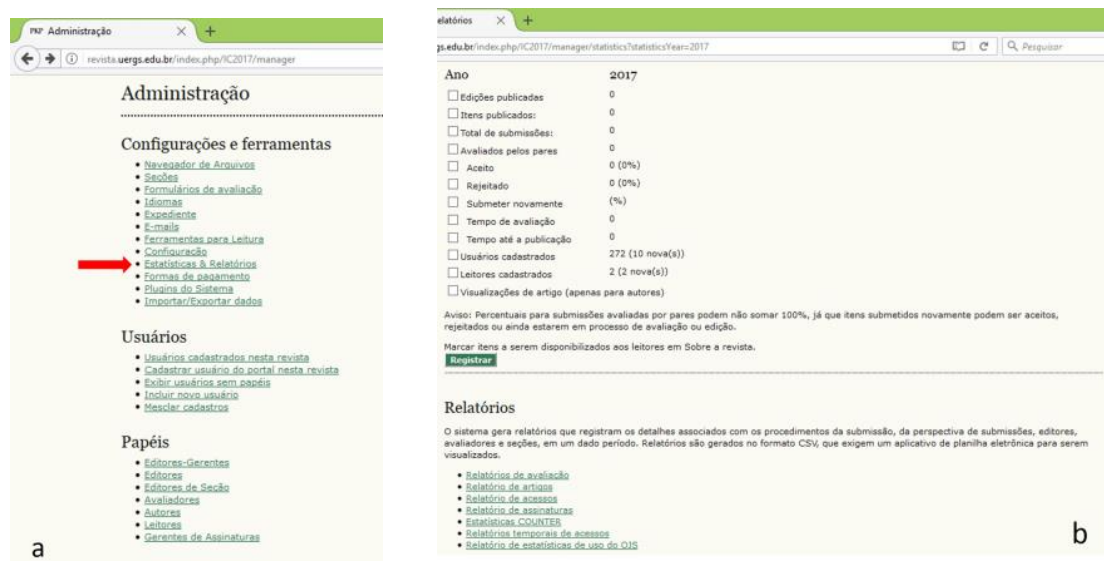

Figura 9a - Administração do sistema que é acessado pelo Editor-gerente para gerar os relatórios e estatísticas (seta indica o item a ser acessado). Figura 9b - Opções de estatísticas e relatórios que podem ser emitidos pelo Editor gerente de forma de obter as listas de projetos submetidos e aceitos no final do processo, conforme utilizado pela Pró-Reitoria de Pesquisa e Pós-Graduação da Universidade Estadual do Rio Grande do Sul (UERGS).

Os relatórios são gerados em arquivos no formato "csv" e para abrir no formato Excel é necessário seguir os seguintes passos: 1) Abrir um arquivo novo no Excel (não abrir o arquivo gerado pelo sistema); 2) No item "Dados" selecionar a opção "Dados de texto"; 3) Selecionar o arquivo "csv" na pasta onde ele foi gerado; 4) Após selecionar o arquivo o "Assistente de importação de texto" irá abrir. Deve-se selecionar o item "Tipo de dados originais" (x) Delimitado, logo abaixo selecionar como "Origem do arquivo" o item "65001: Unicode (UTF 8)" (este passo permite que o arquivo apareça com a redação correta de todas as palavras) e logo abaixo em "Meus dados possuem cabeçalho"; 5) Avançar e selecionar na próxima página o delimitador, no caso a "vírgula" (cada vírgula irá delimitar uma coluna); 6) Avançar e manter o Formato dos dados das colunas como "Geral" ou como "Texto", clicar em "Concluir"; 7) Na sequência clicar em "Ok" 
para que os dados sejam importados na nova planilha. Sugere-se, na sequência, ordenar as colunas pelo ID, excluir colunas que não sejam de interesse e linhas que não sejam utilizadas para então formatar a planilha de acordo com as necessidades de publicação. A ProPPGUERGS utiliza o ID e o título dos projetos para gerar as listas gerais.

\section{Considerações finais}

Após dois anos de uso do SEER pela ProPPG-UERGS em substituição ao sistema de submissão e avaliação de projetos por email afirmamos que a ferramenta pode ser satisfatoriamente utilizada para este fim. Mesmo sem adaptações, em sua forma original, o uso do sistema é viável e apresenta vantagens entre as quais podemos destacar: 1) redução no tempo de avaliação dos projetos, 2) elaboração automática de listas das submissões, 3) facilidade na manutenção de banco de dados e seleção de avaliadores e na distribuição dos projetos entre os mesmos, 4) rapidez na resposta de avaliadores e no envio das declarações de agradecimento para esses, 5) facilidade de envio dos pareceres para os autores, 6) criação e uso de um mesmo Login para todos os processos de submissão e também para a Revista Eletrônica Científica da UERGS, 7) facilidade na elaboração de formulários de avaliação, 8) criação de banco de dados, 8) facilidade da atualização dos perfis dos autores e revisores, 9) possibilidade de acompanhamento das revisões pelos coordenadores, 10) registro no sistema dos projetos avaliados e das avaliações por tempo indeterminado permitindo que haja uma memória institucional, entre outras.

Por ser uma ferramenta com custo praticamente zero, ser intuitiva e por possuir grande superioridade em relação ao e-mail, su- 
gere-se que outras instituições adotem o sistema para este fim e proponham de forma conjunta aos idealizadores do sistema a adequação do mesmo e a consequente disponibilização para este fim.

\section{Referências}

ARELLANO, M. Á. M.; SANTOS, R. dos; FONSECA, R. M.S. da. SEER: Disseminação de um sistema eletrônico para editoração de revistas científicas no Brasil. Arquivistica.net, Rio de Janeiro, v. 1, n. 2 , p. 75-82, $2005 . \quad$ Disponível em: <http://basessibi.c3sl.ufpr.br/brapci/v/a/3949>. Acesso em: 10 Set. 2017.

CALAZANS, A. T. S. Estudo de Caso - uma estratégia de pesquisa. In: MUELLER, Suzana Pinheiro Machado. (Org.). Métodos para a pesquisa em Ciência da Informação. Brasília: Thesaurus, 2007.

CAMPOS, V. F. Gerenciamento da rotina do trabalho do diaa-dia. Belo Horizonte, MG: INDG Tecnologia e Serviços, 2004.

FLICK, U. Introdução à Pesquisa Qualitativa. 3 ed. Porto Alegre: Artmed, 2009.

INSTITUTO BRASILEIRO DE INFORMAÇÃO EM CIÊNCIA E TECNOLOGIA - IBICT. OJS/SEER: sistema eletrônico de editoração de revistas. Brasília, DF: IBICT, Grupo de pesquisa sobre tecnologias para gestão da informação, [2017]. Disponível em: <https://goo.gl/xXfquH>. Acesso em: 5 set. 2017.

LARUCCIA, M. M.; IGNES, P. C., DEGHI, G. J.; GARCIA, M. G. Gerenciamento de Projetos em Pesquisa e Desenvolvimento. Revista de Gestão e Projetos, v. 3, n. 3, p. 109-135, Dez. 2012. Disponível em: <https://goo.gl/RN1bNf> Acesso em: 09 sep. 2017. doi: http://dx.doi.org/10.5585/10.5585.

PUBLIC KNOWLEDGE PROJECT - PKP. 2015. OJS Reaches 10,000. Disponível em: <https://pkp.sfu.ca/2016/12/15/ojs-reaches10000/>. Acesso em: 22 maio 2017. 
PUBLIC KNOWLEDGE PROJECT - PKP. 2016. Location of journals using Open Journal Systems. Disponível em: <https://pkp.sfu.ca/ojs/ojs-usage/ojs- map/>. Acesso em: 22 maio 2017.

PUBLIC KNOWLEDGE PROJECT - PKP. 2017. PKP 2017: International Scholarly ublishing Conference. Disponível em: <https://pkp.sfu.ca/pkp2017/>. Acesso em: 22 maio 2017.

SILVA, I. J. C.; ANDRADES-FILHO, C. O.; COSTA, E. S. 2017. Brazilian university uses Open Journal Systems for submission and assessment process of research projects. In: VI PKP SCHOLARLY PUBLISHING CONFERENCE, 2017, Montreal, Canadá. Disponível em: <https://pkp.sfu.ca/pkp2017/paper/view/589>. Acesso em: 09 set. 2017. 